Article

\title{
Proximate Polyphenolic Composition, Phytochemical Components and Bioactivity Evaluation of Twelve Strawberry (Arbutus unedo L.) Genotypes Grown Under Moroccan Ecological Conditions
}

\author{
Hafida Zitouni ${ }^{1}$, Lahcen Hssaini ${ }^{2}$, Messaoudi Zerhoune ${ }^{3}$, Hamza Ourradii ${ }^{1}$, Manuel Viuda-Martos ${ }^{4}$, \\ Francisca Hernández ${ }^{5}$ and Hafida Hanine ${ }^{1 *}$ \\ ${ }^{1}$ Laboratory of Bioprocess and Bio-interfaces, Faculty of Science and Technics, University Sultan Moulay \\ Slimane, BO 523, Beni-Mellal, Morocco; \\ ${ }^{2}$ Research Unit of Plant Breeding and Plant Genetic Resources Conservation, National Institute for Agricultural \\ Research (INRA), BO 578 Meknes, Morocco; \\ ${ }^{3}$ Departement of Arboriculture, Horticulture and Viticulture, National School of Agriculture, (ENA), BO S/40, \\ Meknes, Morocco; \\ ${ }^{4}$ Dpto. Tecnología Agroalimentaria, IPOA. Escuela Politécnica Superior de Orihuela. (Universidad Miguel \\ Hernández), Ctra Beniel, km 3.2, E-03312 Orihuela (Alicante), Spain); 5 Dpto. Producción Vegetal y \\ Microbiología, Grupo de Investigación de Producción Vegetal y Tecnología, cuela Politécnica Superior de \\ Orihuela (Universidad Miguel Hernández de Elche), Ctra. de Beniel, km 3,2, E- 03312 Orihuela, Alicante, Spain; \\ hafidahanine0@gmail.com \\ Received: date; Accepted: date; Published: date
}

\begin{abstract}
There are not many exhaustive works emphasizing the amount of genetic diversity among the strawberry tree (Arbutus unedo L.) genotypes in Morocco. This work aims to assess the biochemical composition of strawberry tree fruits, as well as to establish the variation of this composition among them. In this study, total phenols, total flavonoids, condensed and hydrolyzable tannins, total anthocyanins and free radical scavenging activity through ABTS were investigated in strawberry tree fruits. Furthermore, qualitative and quantitative analyses of individual phenolic compounds by high-performance liquid chromatography (HPLC) were carried out. Color parameters such as lightness $\left(\mathrm{L}^{*}\right)$, Chroma $\left(\mathrm{c}^{*}\right)$ and hue angle $\left(\mathrm{h}^{\circ}\right)$ were also investigated. All studied variables showed highly significant differences among all samples with the exception of hydrolyzable tannins and chromatic coordinates. Total phenolics varied from $22.63 \pm 1.74$ to $39.06 \pm 2.44 \mathrm{mg} \mathrm{GAE} / \mathrm{g}$ dry wt, total flavonoids varied from $3.30 \pm 0.60$ to $8.62 \pm 1.10 \mathrm{mg} R E / g$ dry wt and total anthocyanins ranged between $0.12 \pm 0.06$ and $0.66 \pm 0.15 \mathrm{mg}$ cya-3-glu/100g dry wt. In addition, condensed and hydrolyzable tannins amounts were in the range of $10.41 \pm 1.07-16.08 \pm 1.50 \mathrm{mg}$ TAE/g dry wt and $4.08 \pm 2.43-6.34 \pm 3.47$ respectively. Moreover, the IC50 value (ABTS) ranged between 1.75 and 19.58 mg AAE/g dry wt. 17 phenolic compounds were detected in strawberry tree fruits. Gallocatechol and catechin were the most abundant phenolic compound. Matrix of correlations revealed significant positive and negative correlations among variables particularly $\mathrm{c}^{*}, \mathrm{a}^{*}$ and $\mathrm{b}^{*}$. Principal component analysis showed that the first three components formed than $68 \%$ of the total inertia. The following variables gallic acid, protocatechuic, gallocatechin, gallic acid derivative, chlorogenic acid, syringic acid, ellagic acid derivative II, $\mathrm{L}^{*}$ and $\mathrm{h}^{*}$ were the most involved in the total variance explained. Hierarchical clustering classified samples into one main cluster, with a single branch. The results highlight a high biochemical diversity within studied strawberry genotypes, which is probably more genetically related.
\end{abstract}

Keywords: Arbutus unedo L; biochemical assessment; antioxidant capacity; phenolic compounds; Morocco 


\section{INTRODUCTION}

The strawberry tree (Arbutus unedo L.) is a wild fruit tree belonging to the Ericaceae family and the genus Arbutus. It is an evergreen fruit tree distributed in the Atlantic-Mediterranean region mainly in southern Europe, North Africa, Ireland, Palestine and Macaronesia [1]. This plant can grow at different altitudes, from sea level to $1200 \mathrm{~m}$, in various types of soils, but preferably acidic soils [2]. Strawberry tree is frequently used in traditional medicine in some countries such as Spain and Morocco 13,4]. It is known for its diuretic, antiseptic and laxative effects as well as for its uses in the treatment of cardiovascular pathologies such as hypertension, atherosclerosis and thrombosis [5-7]The potential health-promoting properties are mainly related to the antioxidant capacity provided by phenolic compounds such as flavonoids, tanins, vitamins ( $\mathrm{C}$ and $\mathrm{E}$ ) and carotenoids [8-13]. Fruits of strawberry tree contain different phenolic compounds, namely gallic acid $[14,15]$, protocatechuique acid, gentitic acid, phydroxybenzoic acid, vanillic acid, m-anisic acid, arbutin, B-D-glucogallin, gallic acid 4-O-B-Dglucopyranoside, 3-Ogalloylquinic acid, 5-Ogalloylquinic acid, 3-O-galloylshikimic acid and 5-Ogalloylshikimic acid. In the past, a few studies were conducted to demonstrate the genetic diversity among strawberry tree genotypes from Turkey, Spain and a few other countries [16-18]. Morphological and biochemical markers have been widely used in breeding studies and in the investigations into diversity of species and the relationship between genotypes, cultivars and their wild parents. More recently, biochemical content, in particular, bioactive content of fruits has been widely searched in terms of their human health benefits. The breeders are now searching to find genotypes that have higher bioactive content in order to use them in cross breeding activities for the purpose of obtaining new cultivars that possess high nutrient value for health [19].

In Morocco, strawberry tree fruits remain underexploited and their consumption lasts seasonal. To our knowledge, there are no scientific studies yet studying biochemical variability among strawberry tree genotypes under Moroccan ecological conditions. Moreover, phenolic compounds and fruit skin color measurements were rarely included in previous works on strawberry tree characterization. In the present work twelve strawberry tree genotypes, belonging to several areas in Morocco, were characterized according to their biochemical markers and skin coordinates color. The main objectives of this study were : (1) to assess the biochemical composition and colorimetric characteristics of strawberry tree fruits ; (2) to determine the correlations between all parameters in order to provide information about the ones that are potentially important in assessing strawberry tree genotypes and (3) to evaluate the biochemical diversity among the strawberry tree genotypes belonging to several areas in Morocco. The genetic variability determined in this study will facilitate strawberry tree breeding and identification of genetic determinants of trait variability.

\section{MATERIALS AND METHODS}

\subsection{Plant material}

Fruits of strawberry tree (Arbutus unedo L.) were harvested during the period between October and November of 2019 from several regions of Morocco where they grow naturally (Table 1). At each site, random samples of fruits were harvested at their full maturity. All selected berries had no diseases and visual blemishes. The samples were frozen at $-20^{\circ} \mathrm{C}$, freeze-dried and ground prior to the analyses. 
Table 1. Origins geographic of the different samples analysed.

\begin{tabular}{|l|c|c|c|}
\hline Origin & Code & Zone & Altitude (m) \\
\hline Chefchaouen & CHF & Rif & 534 \\
\hline Ouazzane & OUZ & Rif & 272 \\
\hline Moulay Driss Zerhoun & MDZ & Middle Atlas & 820 \\
\hline Laanoucer & LAN & Middle Atlas & 1700 \\
\hline Oulmes & OUL & Middle Atlas & 835 \\
\hline Bab Marzouka & BMR & Rif-Middle Atlas & 801 \\
\hline Khenifra & KHN & Middle Atlas & 1390 \\
\hline El Ksiba & KSB & Middle Atlas & 1360 \\
\hline Bin El-Ouidane & BNO & High Atlas & 1420 \\
\hline Ouaouizerth & OUA & Middle-High Atlas & 1050 \\
\hline Tamscart & TAM & Middle Atlas & 1520 \\
\hline Tahnaout & TAH & High Atlas & 1200 \\
\hline
\end{tabular}

\subsection{Chemicals and reagents}

Gallic acid, rutin, Folin Ciocalteu reagent, were purchased from Sigma - Aldrich (St. Petersburg), ABTS [2,2'-azinobis-(3-ethylbenzothiazoline-6-sulfonic acid)] was from HIMEDIA, tannic acid and potassium iodate was from Scharlau, the water was distilled and filtered through a Milli-Qapparatus filter.

\subsection{Extraction procedure}

$1 \mathrm{~g}$ of powder from each sample was mixed with $25 \mathrm{~mL}$ of ethanol $(1: 25, \mathrm{w} / \mathrm{v})$ at $25^{\circ} \mathrm{C}$ for $15 \mathrm{~min}$ using an IKA T-18 digital Ultra-Turrax homogenizer. The homogenate was then centrifuged for 10 minutes at 6,000 rpm and the supernatant was removed from the residue. The latter was homogenized and the supernatant removed as above. The supernatants are then combined and filtered.

\subsection{Total phenols (TP)}

TP was determined by using the Folin-Ciocalteu method described by Ben Salem et al., (2018) [20]. Briefly, $100 \mu \mathrm{L}$ of diluted sample (1/100) with ethanol was added to $400 \mu \mathrm{L}$ of $1 / 10$ diluted Folin Ciocalteu reagent. After 5 minutes, $500 \mu \mathrm{L}$ of $10 \%(\mathrm{w} / \mathrm{v})$ sodium carbonate solution was added. After 1 hour of incubation at room temperature, absorbance at $765 \mathrm{~nm}$ was measured in triplicate. The TP is expressed as gallic acid equivalent per dry weight of strawberry tree fruit (mg GAE/g DW).

\subsection{Total flavonoids (TF)}

TF was measured using the colorimetric method with aluminum chloride (Lamaison and Carnat., 1990) [21]. $1 \mathrm{~mL}$ of the sample was diluted separately then mixed with $1 \mathrm{~mL}$ of a $2 \%$ aluminum chloride solution. The mixture was incubated at room temperature for 15 minutes. Rutin is used to develop the calibration curve. The absorbance is measured at $430 \mathrm{~nm}$ with a spectrophotometer. The results were expressed as rutin equivalent per dry weight of strawberry tree fruit (mg RE/g DW).

\subsection{Condensed tannins (CT)}

The condensed tannins are determined according to the colorimetric method of Folin Denis described by (Joslyn., 1970) [22]. Briefly, $75 \mathrm{~mL}$ of distilled water, $1 \mathrm{~mL}$ of diluted extract, $5 \mathrm{~mL}$ of Folin Denis reagent and $10 \mathrm{~mL}$ of saturated solution (CO3Na2) were introduced into $100 \mathrm{~mL}$ vial. (The saturated solution $\left(\mathrm{CO}_{3} \mathrm{Na}_{2}\right)$ was prepared from $43.75 \mathrm{~g}$ of sodium carbonate dissolved in $100 \mathrm{~mL}$ of hot water $\left(70^{\circ}\right.$ to $\left.80^{\circ} \mathrm{C}\right)$ and after cooling, the solution was filtered and adjusted to $\left.125 \mathrm{~mL}\right)$. After mechanical stirring, the preparation is left to stand for 30 minutes and the optical density is measured at $760 \mathrm{~nm}$. A 
tannic acid standard range was prepared under the same conditions. The results were expressed as tannic acid equivalent per dry weight of strawberry tree fruit (mg TAE/g DW).

\subsection{Hydrolyzable tannins (HT)}

Hydrolyzable tannins are determined according to the method described by (Willis and Allen., 1998) [23]. Brief, $5 \mathrm{~mL}$ of $(2.5 \%) \quad \mathrm{KIO}_{3}$ were placed in test tubes, which were then placed in a water bath at $25^{\circ} \mathrm{C} .1 \mathrm{~mL}$ of diluted extract or standard was added and vortexed for 10 seconds then the tubes were returned to the water bath. After the optimum time (4 min) had elapsed, the absorbance was measured at $550 \mathrm{~nm}$ using a spectrophotometer. A tannic acid standard range was prepared under the same conditions. The results were expressed as tannic acid equivalent per dry weight of strawberry tree fruit (mg TAE/g DW).

\subsection{Total anthocyanins (TA)}

TA content was quantified according to the $\mathrm{pH}$ differential method using two buffer systems : potassium chloride buffer pH $1.0(25 \mathrm{mM})$ and sodium acetate buffer $\mathrm{pH} 4.5(0.4 \mathrm{M})$ (Jakobek et al., 2007 ; Giusti and Wrolstad., 2001) [24,25]. Briefly, $1 \mathrm{~mL}$ of the extract was mixed separately with $4 \mathrm{~mL}$ of each of the two buffers. The absorbance was measured at 510 and $700 \mathrm{~nm}$ after $15 \mathrm{~min}$ of incubation at room temperature. The TA of samples (mg cyanidin-3-glucoside equivalent/100g DW) was calculated by the following equation :

$$
\mathrm{TA}=\left(\mathrm{A}^{*} \mathrm{MW} \mathrm{WF}^{*} 1000 / \varepsilon^{*} \mathrm{~L}\right)
$$

where, A : Absorbance $=[($ A510nm-A700nm $)] \mathrm{pH} 1.0-[($ A510nm-A700nm) $) \mathrm{pH} 4.5 ; \mathrm{MW}:$ molecular weight $(449.2 \mathrm{~g} / \mathrm{mol})$; DF : dilution factor ; $\varepsilon$ : molar absorptivity coefficient of cyanidin-3-glucoside $(26900 \mathrm{~L} / \mathrm{mol} \mathrm{cm})$.

\subsection{Determination of antioxidant capacity}

The antioxidant activity was evaluated using ABTS [2,2'-azinobis-(3-ethylbenzothiazoline-6sulfonic acid)] assay and the results were presented as a mean \pm standard deviation. The method used was described by (Dorman et Hiltunen., 2004) [26]. The ABTS cation radical was prepared by mixing an equal volume of potassium persulfate solution $(2.45 \mathrm{mM})$ with stock solution of ABTS $(7 \mathrm{mM})$. After 16 hours of incubation, the solution was diluted with ethanol to give 0.7 to 0.8 absorbance at $734 \mathrm{~nm}$. $10 \mu \mathrm{L}$ of this freshly prepared solution were added to $990 \mu \mathrm{L}$ of extract and absorbance was measured at 734 $\mathrm{nm}$ after 6 min of incubation. The results were expressed as mg Ascobic Acid Equivalent/g dry weight.

\subsection{Extraction and determination of polyphenolic compound}

\subsubsection{Extraction method}

Samples $(1 \mathrm{~g})$ were mixed with $10 \mathrm{~mL}$ of methanol: water $(80: 20, \mathrm{v} / \mathrm{v})$ and then, the mixtures were sonicated during $30 \mathrm{~min}$, and macerated one hour in refrigeration $\left(4^{\circ} \mathrm{C}\right)$. After the time, the samples were centrifuged for $10 \mathrm{~min}, 8000 \mathrm{~g}$ at $4^{\circ} \mathrm{C}$. The supernatants were collected and the pellets were mixed with $10 \mathrm{~mL}$ of acetone: water $(70: 30, \mathrm{v} / \mathrm{v})$ and the same steps were repeated (sonication, maceration and centrifugation). Then, the supernatants were combined and evaporated to dryness using a rotary evaporator R-205 under reduced pressure, at $40{ }^{\circ} \mathrm{C} .5 \mathrm{~mL}$ of methanol were added to the residue, and the mixture was well shaken in a Vortex for $2 \mathrm{~min}$. Due to the high sugar content present in the samples, which could interfere with the HPLC column, the samples were loaded onto a C18 Sep-Pak cartridge, previously conditioned with $5 \mathrm{~mL}$ of methanol, $5 \mathrm{~mL}$ of pure water, and then with $5 \mathrm{~mL}$ of $0.01 \mathrm{~mol} / \mathrm{L}$ $\mathrm{HCl}$. The cartridge was washed with $5 \mathrm{~mL}$ of pure water and then eluted with acidified methanol $(0.1$ $\mathrm{g} / \mathrm{L} \mathrm{HCl})$. The collected fractions were stored at $-20^{\circ} \mathrm{C}$ until further use.

2.10.2. Determination of polyphenolic compounds 
Polyphenolic profiles of all samples obtained in each phase of in vitro GID were determined by High Performance Liquid Chromatography (HPLC) following the methodology described by (Genskowsky et al., 2016) [27]. A volume of $20 \mu \mathrm{L}$ of the samples were injected into a Hewlett-Packard HPLC series 1200 instrument equipped with C18 column (Mediterranea sea 18, $25 \times 0.4 \mathrm{~cm}, 5 \mathrm{~cm}$ particle size) from Teknokroma, (Barcelona, Spain). Polyphenolic compounds were analyzed in standard and sample solutions using a gradient elution at $1 \mathrm{~mL} / \mathrm{min}$. The mobile phases were composed by formic acid in water $(1: 99, \mathrm{v} / \mathrm{v})$ as solvent $\mathrm{A}$ and acetonitrile as solvent $\mathrm{B}$. The chromatograms were recorded at 280, 320, 360 and $520 \mathrm{~nm}$. Polyphenolic compounds identification was carried out by comparing UV absorption spectra and retention times of each compound with those of pure standards injected in the same conditions.

\subsection{Skin color}

Color determinations were made on fresh $\mathrm{RO}$ and TO, at $25 \pm 1{ }^{\circ} \mathrm{C}$, using a using a NH310 colorimeter (Shenzhen 3NH Technology, China). This spectrophotometer uses an illuminant D65 and a $10^{\circ}$ observer as references. Color data are provided as CIE L*a* ${ }^{*}{ }^{*}$ coordinates, which define the color in a three-dimensional space. $\mathrm{L}^{*}$ indicates lightness, taking values within the range of $0-100$, and $\mathrm{a}^{*}$ and $\mathrm{b}^{*}$ are the chromatic coordinates, green-red and blue-yellow coordinates, respectively. Parameter $\mathrm{a}^{*}$ takes positives values for reddish colors and negative values for the greenish colors, whereas $\mathrm{b}^{*}$ takes positive values for yellowish colors and negative values for bluish colors. Color analyses were run in 25 replicates for each block, which means 10 strawberry fruit per treatment. Each measure was examined with three replications

\subsection{Statistical analysis}

The means were evaluated according to descriptive statistics represented as Mean \pm SE. Data analysis was performed using IBM SPSS v22. Analysis of variance (ANOVA) was performed to test significant differences among the samples. The differences in studied variables were estimated with

Duncan new multiple range (DMRT) test. Correlation coefficients and their levels of significance were calculated using Pearson correlation. Principal Component Analysis was carried out using correlation matrix. In addition, a scatter plot was created according to the first three principal components (PC1, PC2 and PC3). A distance matrix generated from biochemical data was used for cluster analysis based on Euclidian distance to better understand the patterns of variability among the samples.

\section{RESULTS AND DISCUSSION}

All studied variables showed highly significant differences among all samples ( $<<0.05)$, with the exception of hydrolyzable tannins and chromatic coordinates.

\subsection{ANOVA and descriptive analysis}

\subsubsection{Total Phenols (TPC)}

The total phenols content of strawberry tree fruits are presented in Table 2. Significant differences $(p=0.004)$ were observed among the genotypes studied. The total phenols ranged from 22.63 to $39.06 \mathrm{mg}$ GAE/g DW, with an average of $30.20 \mathrm{mg} / \mathrm{g}$ DW. The highest value was recorded in "LAN" $(39.06 \mathrm{mg} / \mathrm{g}$ DW) while the lowest value was observed in "OUA" $(22.63 \mathrm{mg} / \mathrm{g} \mathrm{DW})$. The TPC of strawberry tree fruits reported in this study is higher than those found by other authors ; Doukani and Tabak., (2015) [28] reported a range of 14.74 to $7.025 \mathrm{mg} \mathrm{GAE} / \mathrm{g}$ in Algerian strawberry tree cultivars. In an other study, Seker and Toplu (2010) [29] reported a TPC ranging from 17.7 to $25.8 \mathrm{mg}$ GAE/g). Also, Colak (2019) ; Ruiz-Rodríguez et al., (2011)[30,13] recorded TPV values raging from 483 and $627 \mathrm{mg}$ GAE/100 $\mathrm{g}$ and from 951 to $1973 \mathrm{mg} / 100 \mathrm{~g}$ in Turkish and spanish genotypes respectively. while Vidrih et al., (2013) [19] reported an average of $590 \mathrm{mg} / 100 \mathrm{~g}$ in Croatian fruits. 


\subsubsection{Total flavonoids}

The results of the total flavonoids content are presented in Table 2. A significant variation in total flavonoids was observed at $(\mathrm{p}<0.001)$ among genotypes. The total flavonoids content ranged from 3.30 to $8.62 \mathrm{mg} \mathrm{GAE} / \mathrm{g} \mathrm{DW}$, with an average of $6.44 \mathrm{mg} \mathrm{GAE} / \mathrm{g}$ DW. The highest flavonoids content was observed in "KHN" ( $8.62 \mathrm{mg} / \mathrm{g} \mathrm{DW})$ followed by "TAM" $(8.26 \mathrm{mg} / \mathrm{g} \mathrm{DW})$ and the lowest value was observed in "KSB" (3.30 mg/g DW). These concentrations are higher than those recorded by Jurica et al., (2017) (0.23-0.28 mg EQ/g) and Bouzid et al., (2014) 2.18-6.54 mg EC/g), and by Pallauf et al., (2008) (0.32 $\mathrm{mg} / 100$ g edible portion) [31,32,10].

\subsubsection{Condensed and hydrolysable tannins}

Condensed and hydrolyzable tannins results data are presented in Table 2. A significant variation of condensed tannins was found at $(\mathrm{p}=0.027)$ among genotypes. However, there was no statistical difference for hydrolyzable tannins among genotypes $(\mathrm{p}=0.998)$. On the one hand, The condensed tannins content ranged from 10.41 to $16.08 \mathrm{mg}$ TAE/g DW, with an overall mean of $13.03 \mathrm{mg}$ TAE/g DW. The highest condensed tannins content was observed in "LAN" (16.08 mg TAE/g DW), while the lowest was observed in "BNO" (10.41 mg TAE/g DW). On the other hand, hydrolyzable tannins ranged from 4.08 to $6.34 \mathrm{mg}$ TAE/g DW, with an overall average of $5.37 \mathrm{mg}$ TAE/g DW. The highest value was found in "CHF" (6.34 mg AT/g DW) while the lowest was recorded in "TAH" (4.08 mg AT/g DW). These values were approximately similar with those revealed by (Jurica et al., 2017) [31] who found (16.75$18.92 \mathrm{mg} \mathrm{GAE} / \mathrm{g}$ ) for total tannins.

\subsubsection{Total anthocyanins}

The total anthocyanins content was presented in Table 2. A statistically significant variation at $(\mathrm{p}<0.01)$ was observed among the genotypes studied. The anthocyanins quantity ranged from 0.12 to $0.66 \mathrm{mg}$ equivalent cyanidin-3-glucoside $/ 100 \mathrm{~g}$ DW with an overall mean of 0.34 mg equivalent cyanidin3-glucoside/100g DW. The highest total anthocyanins content was observed in "BMR" (0.66 cyanidin-3glucoside/100g DW), while the lowest was obtained by "OUA" (0.12 cyanidin-3-glucoside/100g DW). These values were lower than the ones published by (Pallauf et al., 2008) [10] (3.77 mg equivalent cyanidine -3-glucoside/100g).

\subsubsection{Antioxidant activity}

The results obtained for antioxidant activity based on the radical scavenging capacity (ABTS) were reported in Table 2. Significant differences $(p<0.001)$ were observed among the genotypes studied. The value of ABTS assay ranged from 1.75 to $19.58 \mathrm{mg}$ ascorbic acid equivalent/g DW, with an overall mean of $7.49 \mathrm{mg}$ ascorbic acid equivalent/g DW. Gündoğdu et al, (2018) (33) analysed the antioxidant capacity (ABTS) of Turkish strawberry tree fruits. They found values ranged between 17.51 and $30.06 \mu \mathrm{mol} \mathrm{TE} / \mathrm{g}$. In other study, Colak, (2019) [30] analysed the antioxidant capacity (ABTS) of Turkish strawberry tree fruits. They found values comprissed between 18.07 and $33.41 \mu \mathrm{mol} \mathrm{TE} / \mathrm{g}$. 
Table 2. Phenolic compound (total phenols, total flavonoids, total anthocyanins, condensed and hydrolyzable tannins) and IC50 value of ABTS at genotypes site.

\begin{tabular}{|c|c|c|c|c|c|c|}
\hline Site & $\begin{array}{c}\mathrm{TP} \\
(\mathrm{mg} \mathrm{GAE} / \mathrm{g} \mathrm{DW})\end{array}$ & $\begin{array}{c}\mathrm{TF} \\
(\mathrm{mg} \mathrm{RE} / \mathrm{g} \mathrm{DW})\end{array}$ & $\begin{array}{c}\mathrm{CT} \\
(\mathrm{mg} \mathrm{TAE} / \mathrm{g} \mathrm{DW})\end{array}$ & $\begin{array}{c}\text { HT } \\
(\mathrm{mg} \text { TAE/g } \\
\text { DW) }\end{array}$ & $\begin{array}{c}\text { TA } \\
(\mathrm{mg} \mathrm{C} 3, \mathrm{G} / 100 \mathrm{~g} \mathrm{DW})\end{array}$ & $\begin{array}{c}\text { ABTS } \\
\text { (mg AAE/g } \\
\text { DW) }\end{array}$ \\
\hline TAM & $29.08 \pm 7.03 \mathrm{abc}$ & $8.26 \pm 1.04 \mathrm{~d}$ & $13.46 \pm 1.75 b c$ & $5.65 \pm 6.25$ & $0.24 \pm 0.15 \mathrm{abc}$ & $1.75 \pm 0.25 a$ \\
\hline $\mathrm{BNO}$ & $31.91 \pm 0.89 \mathrm{bcd}$ & $7.14 \pm 0.74 \mathrm{~cd}$ & $10.41 \pm 1.07 \mathrm{ab}$ & $5.41 \pm 1.45$ & $0.52 \pm 0.23 \mathrm{~cd}$ & $10.58 \pm 2.76 \mathrm{de}$ \\
\hline OUA & $22.63 \pm 1.74 a$ & $7.68 \pm 0.77 \mathrm{~cd}$ & $12.45 \pm 1.70 \mathrm{abc}$ & $4.35 \pm 1.32$ & $0.12 \pm 0.06 a$ & $14.83 \pm 3.71 \mathrm{e}$ \\
\hline $\mathrm{CHF}$ & $28.71 \pm 7.34 \mathrm{abc}$ & $4.49 \pm 0.87 \mathrm{ab}$ & $13.54 \pm 2.01 b c$ & $6.34 \pm 3.47$ & $0.30 \pm 0.14 a b c$ & $3.33 \pm 1.13 \mathrm{ab}$ \\
\hline OUZ & $33.97 \pm 1.93 \mathrm{~cd}$ & $4.60 \pm 1.06 \mathrm{ab}$ & $12.29 \pm 1.45 \mathrm{abc}$ & $5.51 \pm 2.28$ & $0.38 \pm 0.15 \mathrm{abcd}$ & $2.83 \pm 1.46 a$ \\
\hline KSB & $25,37 \pm 5.60 \mathrm{ab}$ & $3.30 \pm 0.60 a$ & $11.62 \pm 1.51 \mathrm{a}$ & $5.14 \pm 3.14$ & $0.15 \pm 0.09 \mathrm{ab}$ & $4.83 \pm 1.88 \mathrm{abc}$ \\
\hline OUL & $25,83 \pm 2.55 \mathrm{ab}$ & $6.96 \pm 1.07 \mathrm{~cd}$ & $11.08 \pm 1.63 \mathrm{ab}$ & $5.93 \pm 2.47$ & $0.16 \pm 0.09 \mathrm{ab}$ & $8.08 \pm 3.64 \mathrm{bcd}$ \\
\hline MDZ & $34,72 \pm 6.53 \mathrm{~cd}$ & $6.09 \pm 0.88 b c$ & $15.58 \pm 1.49 c$ & $6.30 \pm 1.06$ & $0.64 \pm 0.20 \mathrm{~d}$ & $19.58 \pm 4.49 f$ \\
\hline LAN & $39.06 \pm 2.44 d$ & $5.07 \pm 1.04 b$ & $16.08 \pm 1.50 c$ & $5.88 \pm 3.06$ & $0.18 \pm 0.09 \mathrm{ab}$ & $2.25 \pm 0.90 \mathrm{a}$ \\
\hline KHN & $32.00 \pm 3.67 \mathrm{bcd}$ & $8.62 \pm 1.10 \mathrm{~d}$ & $14.66 \pm 2.20 b c$ & $5.05 \pm 3.68$ & $0.35 \pm 0.08 \mathrm{abc}$ & $3.08 \pm 1.13 \mathrm{ab}$ \\
\hline TAH & $27.07 \pm 0.96 \mathrm{abc}$ & $7.07 \pm 0.67 \mathrm{~cd}$ & $13.09 \pm 1.19 \mathrm{abc}$ & $4.08 \pm 2.43$ & $0.43 \pm 0.23 \mathrm{bcd}$ & $9.08 \pm 3.01 \mathrm{~cd}$ \\
\hline BMR & $31.80 \pm 0.69 b c d$ & $8.04 \pm 0.78 d$ & $14.59 \pm 1.88 \mathrm{bc}$ & $4.77 \pm 1.85$ & $0.66 \pm 0.15 d$ & $9.58 \pm 4.31 \mathrm{~cd}$ \\
\hline Mean & 30.20 & 6.44 & 13.03 & 5.37 & 0.34 & 7.49 \\
\hline $\begin{array}{l}\text { Std. } \\
\text { deviatio } \\
\mathrm{n}\end{array}$ & 5.70 & 1.83 & 2.78 & 2.60 & 0.22 & 5.88 \\
\hline $\begin{array}{l}\text { ANOVA } \\
\text { Mean } \\
\text { square }\end{array}$ & $64.00^{* *}$ & $8.83^{* * *}$ & $13.23^{*}$ & $1.56 \mathrm{NS}$ & $0.11^{* *}$ & $93.51^{* * *}$ \\
\hline
\end{tabular}

* denote significant of difference at level $0.05 ;{ }^{* *}$ denote significant of difference at level0.01; ${ }^{* * *}$ denote significant of difference at level 0.001; NS : Not Significant; Data values are means \pm SD; Values in bold represent, in each colunm, the minimum and the maximum for each variable; Different letters (a-l) in the columns represent statistically significant differences among genotypes according to Duncan's multirange test at $\mathrm{p}<0.05$; TP: Total phenols; TF: Total flavonoids; CT : Condensed tannins; HT : Hydrolyzable tannins; TA: Total anthocyanins; GAE: Gallic acid equivalent; RE: Rutin equivalent; TAE : Tannic acid; C3,G : Cyanidin-3-glucoside equivalent; AAE : Ascorbic acid equivalent.

\subsubsection{Profil of polyphenolic Compounds}

A total of 17 phenolic compounds have been identified in strawberry tree fruits. The results obtained were summerized in Table 3. Significant variations in phenolic compounds were found at $p$ $<0.001$ among genotypes. Gallocatechol was present in dominant amounts in all genotypes with the exception of "CHF" and "MDZ" where the dominant compound was catechin. The concentration of gallocatechol differed between genotypes. The highest level reported in "OUZ" (79.88 mg/100 gDW) and the lowest in "CHF" (16.15 mg/100g DW). Catechin was found in higher amounts in all genotypes. "OUZ" had the highest concentration $(65.53 \mathrm{mg} / 100 \mathrm{~g}$ DW) of catechin, and "BNO" had the lowest concentration (13.99 mg/100g DW). Protocatechuic acid was present in significantly higher amounts in "OUZ" (6.98 mg/100g DW) and significantly lower amounts in "MDZ" (1.84 mg/100g DW). Gallic acid was present in significantly higher amounts in "OUZ"(58.07 mg/100g DW), the lowest amount was recorded in "MDZ"(4.56 mg/100g DW). Gallic acid derivatives were detected in all genotypes. The highest amount was present in "OUZ"(22.02 mg/100g DW), and the lowest in "CHF"(4.98 mg/100g DW). The concentration of syringic acid differed significantly between genotypes, with the highest level in "OUZ"(16.55 mg/100g DW) and the lowest in "CHF"(4.27 mg/100g DW). Among the phenolic acid group, chlorogenic acid was significantly higher in all genotypes. The highest level was observed in "TAH"(27.42 mg/100g DW), and the lowest in "CHF"(5.55 mg/100g DW). Ellagic acid was also noticed in all genotypes. The highest level was found in "OUL"(39.29 mg/100g DW) and the lowest in "CHF"(8.42 
$\mathrm{mg} / 100 \mathrm{~g} \mathrm{DW})$. Ellagic acid derivatives I and II were seen in all genotypes. The highest levels were found in "OUZ"(30.88 mg/100g DW) and $(36.56 \mathrm{mg} / 100 \mathrm{~g} \mathrm{DW})$ respectively, however, the lowest levels were found in "KHN"(7.79 mg/100g DW) and "CHF"(8.97 mg/100g DW), respectively. Other minor compounds such as Quercetin-3-xyloside, Quercetin-3-galactoside, Quercetin-3-glucoside, Rutin, Cyanidine-3-glucoside, Cyanidine-3-5-diglucoside and Cyanidine-3-arabinoside were also identified. "OUZ" had the highest amount of quercetin-3-xyloside (7.92 mg/100g DW), while "MDZ" had the lowest amount $(1.43 \mathrm{mg} / 100 \mathrm{~g} \mathrm{DW})$. "KSB" recoreded the highest amount of quercetin-3-galactoside (3.46 $\mathrm{mg} / 100 \mathrm{~g} \mathrm{DW})$, while "KHN" recoreded the lowest amount (1.00 mg/100g DW). Quercetin-3-glucoside was significantly higher in all genotypes. The highest amount was observed in "TAM" $(3.21 \mathrm{mg} / 100 \mathrm{~g}$ $\mathrm{DW})$, and the lowest in "KHN" $(0.98 \mathrm{mg} / 100 \mathrm{~g} \mathrm{DW})$. Rutin compound was present in lower amounts in all genotypes. "BMR" had the highest quantity of rutin $(2.26 \mathrm{mg} / 100 \mathrm{~g} \mathrm{DW})$ whereas the lowest amount recorded in "OUA" (0.67 mg/100g DW). Similarly, cyanidin-3-glucoside was spotted in all genotypes. "TAH" contained the highest amount $(7.21 \mathrm{mg} / 100 \mathrm{~g} \mathrm{DW})$ as the lowest was recorded in "OUA" $(0.36$ $\mathrm{mg} / 100 \mathrm{~g}$ DW). Concerning the last two compound which are cyanidine-3-5-diglucoside and cyanidine3 -arabinoside, they were identified within only six genotypes. The lowest amounts of them recorded in "CHF" $(0.61 \mathrm{mg} / 100 \mathrm{~g} \mathrm{DW})$ and $(0.36 \mathrm{mg} / 100 \mathrm{~g} \mathrm{DW})$ respectively whereas the largest ones were observed in "TAH" (3.30 mg/100g DW) and $(1.64 \mathrm{mg} / 100 \mathrm{~g} \mathrm{DW})$, respectively. Our results are consistent with those of (Ganhão et al., 2010) [34] who had found catechin, gallic acid, ellagic acid, ellagic acid, chlorogenic acid, rutin and cyanidin-3-glucoside in strawberry tree fruits collected in Spain. However, (Ayaz et al., 2000) [14] reported that gallic acid (10.7 mg/g DW) was the main phenolic compound in strawberry tree fruits collected in Turkey, followed by protocatechic acid, gentisic acid, p-hydroxybenzoic acid, vanillic acid and m-anisic acid. Distinctively, (Mendes et al., 2011) [35] had identified other phenolic compounds in strawberry tree fruits collected in north-eastern Portugal. These compounds are gallic acid glucoside, galloylquinic acid, quinic acid derivative, proanthocyanidin dimer, galloylshikimic acid, digalloylquinic acid, digalloylshikimic acid, catechin monomer, proanthocyanidin trimer, strictinin ellagitannin, ellagitannin derivative, galloyl derivative, trigalloylshikimic acid, myricetin rhamnoside, quercetin glucoside, gallotannin and ellagic acid rhamnoside. 
Table 3. Polyphenolic compounds at genotypes site (mean \pm SD in mg/100g DW) .

\begin{tabular}{|c|c|c|c|c|c|c|c|c|c|c|c|c|c|}
\hline Site & $\overline{\text { GA }}$ & $\overline{\mathbf{P C}}$ & \multicolumn{2}{|l|}{$\overline{G C}$} & \multicolumn{2}{|c|}{ GAD } & \multicolumn{2}{|c|}{ CAT } & \multicolumn{2}{|r|}{$\overline{C A}$} & \multicolumn{2}{|r|}{$\mathbf{S A}$} & EADI \\
\hline TAM & $11.75 \pm 0.01 \mathrm{e}$ & $2.95 \pm 0.00 f$ & \multicolumn{2}{|c|}{$43.20 \pm 0.08 f$} & \multicolumn{2}{|c|}{$10.56 \pm 0.01 \mathrm{~h}$} & \multicolumn{2}{|c|}{$37.46 \pm 0.07 \mathrm{~h}$} & \multicolumn{2}{|c|}{$17.41 \pm 0.00 \mathrm{~g}$} & \multicolumn{2}{|c|}{$7.68 \pm 0.00 e$} & $17.12 \pm 0.01 \mathrm{~g}$ \\
\hline BNO & \multirow{2}{*}{$\begin{array}{l}15.37 \pm 0.00 g \\
12.52 \pm 0.00 f\end{array}$} & $2.17 \pm 0.00 c$ & \multicolumn{2}{|c|}{$27.56 \pm 0.02 c$} & \multicolumn{2}{|c|}{$8.57 \pm 0.00 d$} & \multicolumn{2}{|c|}{$13.99 \pm 0.02 a$} & \multicolumn{2}{|c|}{$18.92 \pm 0.01 \mathrm{~h}$} & \multicolumn{2}{|c|}{$7.41 \pm 0.00 d$} & $15.47 \pm 0.00 f$ \\
\hline OUA & & $2.11 \pm 0.00 b$ & \multirow{2}{*}{\multicolumn{2}{|c|}{$\begin{array}{c}40.35 \pm 0.01 \mathrm{e} \\
16.15 \pm 0.03 \mathrm{a}\end{array}$}} & $9.61 \pm$ & $0.00 f$ & $29.70=$ & $=0.01 \mathrm{f}$ & 14.11 & $\pm 0.00 d$ & & $87 \pm 0.00 b$ & $14.22 \pm 0.00 d$ \\
\hline $\mathbf{C H F}$ & $6.09 \pm 0.00 b$ & $2.57 \pm 0.01 \mathrm{e}$ & & & $4.98=$ & $0.00 \mathrm{a}$ & $49.36=$ & $=0.01 \mathrm{k}$ & 5.55 & \pm O.ooa & 4.2 & $27 \pm 0.00 a$ & $13.32 \pm 0.01 c$ \\
\hline ouz & $58.07 \pm 0.021$ & $1 \quad 6.98 \pm 0.011$ & k $\quad 79.88 \pm 0$ & .071 & $22.02 \pm$ & 0.011 & $65.53=$ & $=0.041$ & 30.25 & $5 \pm 0.021$ & 16.5 & $55 \pm 0.00 k$ & $30.88 \pm 0.041$ \\
\hline $\begin{array}{l}\text { KS B } \\
\text { OUL }\end{array}$ & $\begin{aligned} 21.88 & =0.01 \mathrm{i} \\
10.93 & =0.01 \mathrm{~d}\end{aligned}$ & $\begin{array}{r}3.14 \pm 0.01 \mathrm{~g} \\
4.81 \pm 0.00 \mathrm{i}\end{array}$ & $\begin{aligned} 45.23 & =0 . \\
56.81 & =0\end{aligned}$ & $\begin{array}{l}05 \mathrm{~g} \\
02 \mathrm{i}\end{array}$ & $\begin{array}{r}10.15 \pm \\
14.25 \pm\end{array}$ & $0.01 \mathrm{~g}$ & $\begin{array}{l}33.60 \pm \\
19.40 \pm\end{array}$ & $\begin{array}{l}0.03 \mathrm{~g} \\
0.01 \mathrm{~b}\end{array}$ & $\begin{array}{l}14.50 \\
23.73\end{array}$ & $\begin{array}{l}0 \pm 0.00 e \\
3 \pm 0.01 i\end{array}$ & & $\begin{array}{l}40 \pm 0.01 d \\
10 \pm 0.00 i\end{array}$ & $\begin{array}{l}18.59=0.01 i \\
19.31=0.01 i\end{array}$ \\
\hline MOz & $4.56 \pm 0.02 \mathrm{a}$ & $1.84 \pm 0.00$ & a $\quad 17.11 \pm 0$ & $07 \mathrm{~b}$ & $7.36 \pm$ & $0.01 \mathrm{c}$ & $38.98=$ & $=0.05 j$ & 12.10 & $\pm 0.01 b$ & & $17 \pm 0.01 c$ & $17.22=0.05 \mathrm{~h}$ \\
\hline LAN & $35.83 \pm 0.02 j$ & $4.18=0.03 h$ & $58.79 \pm 0$. & $33 \mathrm{j}$ & $7.30 \pm$ & $0.01 \mathrm{~b}$ & $22.09=$ & $=0.08 c$ & 12.48 & $8 \pm 0.02 c$ & & $94 \pm 0.02 h$ & $8.05 \pm 0.03 b$ \\
\hline KHN & $7.42 \pm 0.00 c$ & $2.32 \pm 0.00 c$ & $34.00=0$ & $01 d$ & $9.25 \pm$ & $0.00 e$ & $29.47 \pm$ & $=0.01 \mathrm{e}$ & 14.61 & $1 \pm 0.00 f$ & & $84 \pm 0.00 g$ & $7.79 \pm 0.01 \mathrm{a}$ \\
\hline TAH & $36.93 \pm 0.02 k$ & $5.90 \pm 0.01 j$ & $65.31 \pm 0$. & $04 \mathrm{k}$ & $14.54 \pm$ & $0.02 k$ & $24.68 \pm$ & $0.08 d$ & 27.42 & $2 \pm 0.02 k$ & & $80 \pm 0.01 f$ & $25.06 \pm 0.04 k$ \\
\hline BMR & $15.45 \pm 0.00 h$ & $4.18 \pm 0.00 h$ & $54.35=0$. & $02 \mathrm{~h}$ & $12.75 \pm$ & $0.00 \mathrm{i}$ & $38.55=$ & $=0.01 \mathrm{i}$ & 20.74 & $4 \pm 0.00 i$ & & $.85 \pm 0.00 j$ & $14.95 \pm 0.01 \mathrm{e}$ \\
\hline Mean & 19.73 & 3.60 & 44.90 & & 10.5 & & 33. & 57 & & 17.65 & & 8.24 & 16.83 \\
\hline Std. deviation & 15.57 & 1.59 & 18.76 & & 4.3 & & 13. & 63 & & 6.79 & & 3.16 & 6.26 \\
\hline $\begin{array}{l}\text { ANOVA } \\
\text { Mean square }\end{array}$ & $771.20 * * *$ & $8.06 * * *$ & $1119.71 *$ & & 60.68 & $* * *$ & 5910 & * & 16. & * & & $*$ & $124.88 * * *$ \\
\hline Site & EADII & EA & C3G & & Q3X & & $\mathbf{R T}$ & Q3G & & Q3G & & C3,5 DG & C3A \\
\hline TAM & $17.83 \pm 0.01 \mathrm{~g}$ & $20.86 \pm 0.01 \mathrm{~h}$ & $0.57 \pm 0.00 c$ & 3.96 & $\pm 0.01 \mathrm{~h}$ & $1.42 \pm$ & $\pm 0.01 i$ & $3.40 \pm$ & $\overline{0.02 i}$ & $3.21 \pm 0$. & $.01 \mathrm{~g}$ & n.d & n.d \\
\hline BNO & $13.49 \pm 0.01 d$ & $21.09 \pm 0.02 i$ & $0.70 \pm 0.00 d$ & 3.24 & $\pm 0.01 \mathrm{~g}$ & $0.75 \pm$ & $\pm 0.00 \mathrm{~b}$ & $1.33 \pm 0$ & $0.01 \mathrm{~b}$ & $2.66 \pm 0.0$ & 1 def & n.d & $\mathrm{n}$. \\
\hline OUA & $13,94 \pm 0.00 e$ & $16.91 \pm 0.00 e$ & $0.36 \pm 0.00 a$ & 2.08 & $\pm 0.00 c$ & $0.67 \pm$ & $\pm 0.00 \mathrm{a}$ & $1.42 \pm C$ & $0.00 \mathrm{c}$ & $1.54 \pm 0 . C$ & $\mathrm{OOb}$ & n.d & n.d \\
\hline CHF & $8.97 \pm 0.01 a$ & $8.42 \pm 0.01 \mathrm{a}$ & $2.27 \pm 0.00 \mathrm{e}$ & $2.11=$ & $\pm 0.01 \mathrm{~cd}$ & $1.17 \pm$ & $\pm 0.00 \mathrm{~g}$ & $1.66 \pm 0$ & $0.00 d$ & $2.11 \pm 0.0$ & o1cd & $0.61 \pm 0.00 \mathrm{a}$ & $0.36 \pm 0.01 a$ \\
\hline OuZ & $\begin{array}{c}36.56 \pm \\
0.03 \mathrm{k}\end{array}$ & $36.38 \pm 0.03 k$ & $6.15 \pm 0.00 i$ & 7.92 & $\pm 0.04 k$ & $1.70=$ & $\pm 0.01 j$ & $2.82 \pm 0$ & $0.01 \mathrm{~g}$ & $2.90=0.0$ & 1 efg & $2.62 \pm 0.01 \mathrm{e}$ & $1.31 \pm 0.02 \mathrm{e}$ \\
\hline KSB & $15.96 \pm 0.01 \mathrm{f}$ & $18.00=0.00 f$ & $0.43 \pm 0.01 b$ & 4.09 & $\pm 0.01 i$ & $1.06 \pm$ & $\pm 0.01 \mathrm{e}$ & $3.46 \pm$ & $0.02 \mathrm{j}$ & $2.89 \pm 0.0$ & Oefg & n.d & n.d \\
\hline OUL & $21.65 \pm 0.01 j$ & $39.29 \pm 0.011$ & $0.69 \pm 0.00 d$ & 2.14 & $\pm 0.00 \mathrm{~d}$ & $1.43 \pm$ & $\pm 0.00 \mathrm{i}$ & $1.79 \pm c$ & $0.01 \mathrm{e}$ & $1.71 \pm 0.0$ & $01 \mathrm{bc}$ & n.d & n.d \\
\hline MDz & $9.40 \pm 0.04 b$ & $14.34=0.02 d$ & $5.68 \pm 0.01 \mathrm{~h}$ & $\mathbf{1 . 4 3}$ & $\pm 0.01 \mathrm{a}$ & $0.96 \pm$ & $\pm 0.00 d$ & $3.02 \pm 0$ & $0.01 \mathrm{~h}$ & $2.12 \pm 0.0$ & $01 \mathrm{~cd}$ & $1.59 \pm 0.02 c$ & $1.07 \pm 0.00 d$ \\
\hline LAN & $9.40 \pm 0.10 b$ & $10.27 \pm 0.05 c$ & $0.57 \pm 0.02 c$ & 2.72 & $\pm 0.03 e$ & $1.26 \pm$ & $\pm 0.01 \mathrm{~h}$ & $3.03 \pm 0$ & $0.04 \mathrm{~h}$ & $2.54 \pm 0.0$ & $02 \mathrm{de}$ & n.d & n.d \\
\hline KHN & $9.91 \pm 0.00 c$ & $10.16 \pm 0.01 b$ & $3.04 \pm 0.00 f$ & 1.64 & $\pm 0.00 \mathrm{~b}$ & $1.10=$ & $\pm 0.00 f$ & $1.00 \pm 0$ & $0.01 \mathrm{a}$ & $0.98 \pm 0$. & $.00 a$ & $0.67 \pm 0.00 b$ & $0.89 \pm 0.00 b$ \\
\hline TAH & $21.39 \pm 0.02 i$ & $33.73 \pm 0.02 j$ & $7.21 \pm 0.01 \mathrm{j}$ & 2.81 & $\pm 0.03 \mathrm{f}$ & $0.90 \pm$ & $\pm 0.02 \mathrm{c}$ & $2.73 \pm c$ & $0.02 f$ & $2.27 \pm 0 . c$ & $01 \mathrm{~d}$ & $3.30 \pm 0.02 f$ & $1.64 \pm 0.01 \mathrm{f}$ \\
\hline BMR & $19.01 \pm 0.01 \mathrm{~h}$ & $19.50=0.01 \mathrm{~g}$ & $4.24 \pm 0.00 \mathrm{~g}$ & 6.31 & $\pm 0.01 j$ & $2.26 \pm$ & $\pm 0.01 \mathrm{k}$ & $1.35 \pm 0$ & $0.00 \mathrm{~b}$ & $3.10=1.0$ & $02 \mathrm{fg}$ & $1.63 \pm 0.00 \mathrm{~d}$ & $1.01 \pm 0.01 \mathrm{c}$ \\
\hline Mean & 16.46 & 20.75 & 2.66 & & 3.37 & & .22 & 2.25 & & 2.34 & & 0.87 & 0.52 \\
\hline S td. deviation & 7.62 & 10.12 & 2.48 & & 1.91 & & .43 & 0.88 & & 0.70 & & 1.12 & 0.60 \\
\hline $\begin{array}{l}\text { ANOVA } \\
\text { Mean square }\end{array}$ & $184.85 * * *$ & $325.95^{* * *}$ & $19.49 * * *$ & 11. & $58 * * *$ & 0.59 & $9 * * *$ & $2.46^{*}$ & & $1.38^{*}$ & & $4.02 * * *$ & $1.14 * * *$ \\
\hline
\end{tabular}

*** denote significant of difference at level 0.001 ; Data values are means \pm SD ; Values in bold represent, in each colomn, the minimum and the maximum for each variable; n.d : not determined; Different letters (a-l) in columns represent statistically significant differences among genotypes according to Duncan's multi-range test at $\mathrm{p}<0.05$. 


\subsubsection{Skin Color}

Color measurements data are reported in Table 4, there were no statistical differences between strawberry tree genotypes for all color indices $L^{*}, a^{*}, b^{*}, c^{*}$ and $h^{\circ}$. Data showed that Lightening $\left(L^{*}\right)$ values ranged from 25.83 to 50.78. The genotypes "LAN" and "BMR" had the brightest skin color (50.78 and 39.09, respectively). Whereas, "BNO" and "OUA" recorded the lowest values of $\mathrm{L}^{*}$ (25.83 and 26.27, respectively). $\mathrm{a}^{*}$ and $\mathrm{b}^{*}$ values ranged from 28.93 to 58.91 and from 70.85 to 93.73 , respectively. "TAM" showed the highest $a^{*}$ value while "LAN" showed the least value. The $b^{*}$ value was higher (93.73) in "TAM", while the lowest $b^{*}$ value was found in "OUL" (70.85). According to positive values of $a^{*}$ and $\mathrm{b}^{*}$, strawberry tree fruits included reddish orange to deep crimson red fruit colors. The Chroma $\left(\mathrm{c}^{*}\right)$ was higher in genotypes with clear and bright fruit skin color, where it varied generally between 78.30 and 110.17. The highest and the least red colour intensity were found in "TAM" and "LAN" genotypes, respectively. The hue angle $\left(\mathrm{h}^{\circ}\right)$, ranged between $54.70^{\circ}$ and $66.45^{\circ}$. The highest $\mathrm{h}^{\circ}$ value was observed for "LAN" $\left(66.45^{\circ}\right)$, while the lowest value was observed for "OUA" $\left(54.70^{\circ}\right)$. All strawberry tree genotypes were lighter (higher $\mathrm{L}^{*}$ values) and tended to be more red (higher $\mathrm{a}^{*}$ values) and yellower (higher $b^{*}$ values). Furthermore, the genotypes showed higher values of chroma $\left(c^{*}\right)$ and hue angle $\left(h^{\circ}\right)$ corresponding to a lighter color. Therefore, skin color evaluation using these coordinates is of great importance in characterization and assessment of fruits quality and maturity. These results are globally, in accordance with several studies. Islam and Pehlivan., (2016)[(36] reported average $\mathrm{L}^{*}$, $\mathrm{a}^{*}$ and $\mathrm{b}^{*}$ values of 40 genotypes as 47.26, 37.07 and 26.89, respectively. Also, (Colak., 2019) [30] reported average $\mathrm{L}^{*}$, $\mathrm{a}^{*}$ and $b^{*}$ values of 15 genotypes as 44.30, 37.53 and 23.88 respectively. According to the literature, the color coordinates is, particularly correlated to the antioxidant compound, essentially phenols (anthocyanins, tannins, catechins, etc.) and carotenoids (lycopene, betacarotene, etc.) (Badgujar et al., 2014; Wang et al., 2017) [37,38].

Table 4. Colorimetric characters of the strawberry fruits at genotypes site.

\begin{tabular}{|c|c|c|c|c|c|}
\hline Site & $L^{*}$ & $a^{*}$ & $b^{*}$ & $c^{*}$ & $\mathrm{~h}^{\circ}$ \\
\hline TAM & $30.30 \pm 3.99$ & $58.91 \pm 15.96$ & $93.73 \pm 20.41$ & $110.17 \pm 25.69$ & $58.71 \pm 1.53$ \\
\hline $\mathrm{BNO}$ & $25.83 \pm 9.86$ & $51.80 \pm 11.55$ & $84.51 \pm 11.47$ & $100.59 \pm 15.92$ & $54.80 \pm 7.29$ \\
\hline OUA & $26.27 \pm 9.44$ & $54.87 \pm 12.57$ & $89.69 \pm 16.76$ & $106.18 \pm 21.82$ & $54.70 \pm 6.42$ \\
\hline $\mathrm{CHF}$ & $35.47 \pm 15.78$ & $48.18 \pm 19.71$ & $86.14 \pm 13.37$ & $100.63 \pm 21.13$ & $58.09 \pm 11.90$ \\
\hline OUZ & $37.79 \pm 15.29$ & $39.47 \pm 21.25$ & $77.88 \pm 14.14$ & $89.36 \pm 21.95$ & $60.78 \pm 14.24$ \\
\hline KSB & $33.32 \pm 10.60$ & $40.79 \pm 17.11$ & $73.88 \pm 16.05$ & $86.08 \pm 22.60$ & $58.36 \pm 10.06$ \\
\hline OUL & $32.18 \pm 3.16$ & $38.39 \pm 13.38$ & $70.85 \pm 12.82$ & $82.20 \pm 17.91$ & $58.14 \pm 9.17$ \\
\hline MDZ & $35.03 \pm 16.17$ & $48.38 \pm 16.54$ & $84.92 \pm 6.54$ & $99.62 \pm 13.08$ & $57.29 \pm 11.74$ \\
\hline LAN & $50.78 \pm 3.44$ & $28.93 \pm 15.10$ & $70.84 \pm 7.65$ & $78.30 \pm 12.00$ & $66.45 \pm 12.38$ \\
\hline KHN & $33.42 \pm 21.21$ & $44.37 \pm 21.28$ & $81.68 \pm 12.34$ & $95.05 \pm 20.63$ & $58.81 \pm 13.83$ \\
\hline $\mathrm{TAH}$ & $32.65 \pm 5.19$ & $38.19 \pm 11.84$ & $74.16 \pm 10.22$ & $85.08 \pm 14.64$ & $59.29 \pm 8.82$ \\
\hline BMR & $39.09 \pm 5.01$ & $46.38 \pm 17.55$ & $86.23 \pm 14.16$ & $98.21 \pm 19.41$ & $59.91 \pm 8.95$ \\
\hline Mean & 34.34 & 44.89 & 81.21 & 94.29 & 58.78 \\
\hline Std. deviation & 11.43 & 15.85 & 13.39 & 18.71 & 9.00 \\
\hline $\begin{array}{l}\text { ANOVA } \\
\text { Mean square }\end{array}$ & $128.11 \mathrm{NS}$ & 206.61 NS & $172.51 \mathrm{NS}$ & 298.96 NS & $27.30 \mathrm{~S}$ \\
\hline
\end{tabular}

NS: Not Significant; Data values are means \pm SD; Values in bold represent, in each colunm, the minimum and the maximum for each variable.

\subsection{Correlation among variables}

In order to identify the relations between biochemical traits, all variables were subjected to bivariate correlation using the Pearson coefficient. Significant correlations at the level of 0.05 or 0.01 are summarized in the Table 5. In the current study, the correlation value was found between condensed 
tannins and total phenols $\left(\mathrm{r}=0.631^{*}\right)$. Samely, links were noticed between protocatechic acid and gallic acid $\left(\mathrm{r}=0.841^{* *}\right)$ as well as between gallocatechin and both gallic acid $\left(\mathrm{r}=0.834^{* *}\right)$ and protocatechic acid $\left(\mathrm{r}=0.913^{* *}\right)$. Also, derivatives gallic acid was correlated to gallic acid $\left(\mathrm{r}=0.717^{* *}\right)$, protocatechic acid $(\mathrm{r}$ $\left.=0.854^{* *}\right)$ and gallocatechin $\left(\mathrm{r}=0.841^{* *}\right)$. The correlation between chlorogenic acid and each of the following parameters : gallic acid, protocatechic acid, gallocatechin and gallic acid derivatives were respectively $0.651^{*}, 0.812^{* *}, 0.806^{* *}$ and $0.927^{* *}$. The results obtained showed also, positive correlations between syringic acid and each of the following parameters : gallic acid $\left(\mathrm{r}=0.705^{*}\right)$, protocatechic acid $\left(\mathrm{r}=0.771^{* *}\right)$, gallocatechin $\left(\mathrm{r}=0.764^{* *}\right)$, gallic acid derivatives $\left(\mathrm{r}=0.870^{* *}\right)$ and chlorogenic acid $(\mathrm{r}$ $\left.=0.770^{* *}\right)$. In the same way, the study revealed links between derivatives ellagic acid I and gallic acid ( $\mathrm{r}$ $\left.=0.619^{*}\right)$, protocatechic acid $\left(\mathrm{r}=0.710^{* *}\right)$, gallic acid derivatives $\left(\mathrm{r}=0.821^{* *}\right)$, chlorogenic acid $\left(\mathrm{r}=0.769^{* *}\right)$ and syringic acid $\left(\mathrm{r}=0.590^{*}\right)$. Correspondingly, it conveyed correlations between derivatives ellagic acid II and gallic acid $\left(\mathrm{r}=0.718^{* *}\right)$, protocatechic acid $\left(\mathrm{r}=0.839^{* *}\right)$, gallocatechin $\left(\mathrm{r}=0.800^{* *}\right)$, gallic acid derivatives $\left(r=0,976^{* *}\right)$, chlorogenic acid $\left(r=0.883^{* *}\right)$, syringic acid $\left(r=0.849^{* *}\right)$ and ellagic acid I derivatives $\left(\mathrm{r}=0.872^{* *}\right)$. As far as ellagic acid concerned, the study portrayed a relationship between it and protocatechic acid $\left(\mathrm{r}=0.757^{* *}\right)$, gallocatechin $\left(\mathrm{r}=0.692^{*}\right)$, gallic acid derivatives $\left(\mathrm{r}=0.849^{* *}\right)$, chlorogenic acid $\left(\mathrm{r}=0.906^{* *}\right)$, syringic acid $\left(\mathrm{r}=0.590^{*}\right)$, ellagic acid derivatives $\mathrm{I}\left(\mathrm{r}=0.822^{* *}\right)$ and ellagic acid derivatives II $\left(\mathrm{r}=0.847^{* *}\right)$. Equally, the results depicted connections between cyanidine-3,5diglucoside and protocatechic acid $\left(\mathrm{r}=0.631^{*}\right)$, gallic acid derivatives $\left(\mathrm{r}=0.581^{*}\right)$, chlorogenic acid $(\mathrm{r}=$ $\left.0,583^{*}\right)$, ellagic acid I derivatives $\left(r=0.660^{*}\right)$ and cyanidin-3- glucoside $\left(r=0.972^{* *}\right)$. They showed also ties between cyanidin-3-arabinoside and anthocyanins $\left(\mathrm{r}=0.636^{*}\right)$, cyanidine-3-glucoside $\left(\mathrm{r}=0.984^{* *}\right)$ as well as cyanidine 3,5 diglucoside $\left(\mathrm{r}=0.956^{* *}\right)$. Relations between the following variables were also manifested by the same study : cyanidine-3-glucoside and anthocyanins $\left(\mathrm{r}=0.656^{*}\right)$, rutin and syringic acid $\left(r=0.705^{*}\right)$ and finally quercetin-3-glucoside and quercetin-3-galactoside $\left(r=0.606^{*}\right)$. Regarding color indices, $\mathrm{L}^{*}$ revealed positive links with total phenols $\left(\mathrm{r}=0.713^{* *}\right)$ and condensed tanins $\left(\mathrm{r}=0.591^{*}\right)$. Similarly, $b^{*}$ with $a^{*}\left(r=0.936^{* *}\right)$. However, $a^{*}$ showed negative ones with gallic acid $\left(r=-0.576^{*}\right)$, protocatechic acid $\left(r=-0.607^{*}\right)$ and $L^{*}\left(r=-0.727^{* *}\right)$. Unsteadingly, $c^{*}$ conveyed negative connections with both protocatechic acid $\left(r=-0.609^{*}\right)$ and $L^{*}\left(r=-0.578^{*}\right)$, and positive ones with $\mathrm{a}^{*}\left(\mathrm{r}=0.972^{* *}\right)$ and $b^{*}\left(r=0.990^{* *}\right)$. Likewise, $h^{*}$ had negative links with both $a^{*}\left(r=-0.747^{* *}\right)$ and $c^{*}(r=-0.630)$, and positive ones with total phenols $\left(\mathrm{r}=0.646^{*}\right)$ and $\mathrm{L}^{*}\left(\mathrm{r}=0.943^{* *}\right)$. The correlation coefficients may provide information on the parameters that are potentially important in assessing strawbery tree genotypes (Norman et al. 2011) [39]. Significant and strong correlated traits can be used to predict other ones, and could be considered of importance for genotypes characterization and discrimination (Podgornik et al. 2010) [40]. 
Table 5. Correlation coefficients among biochemical parameters analyzed.

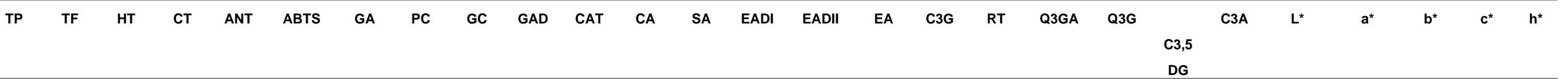

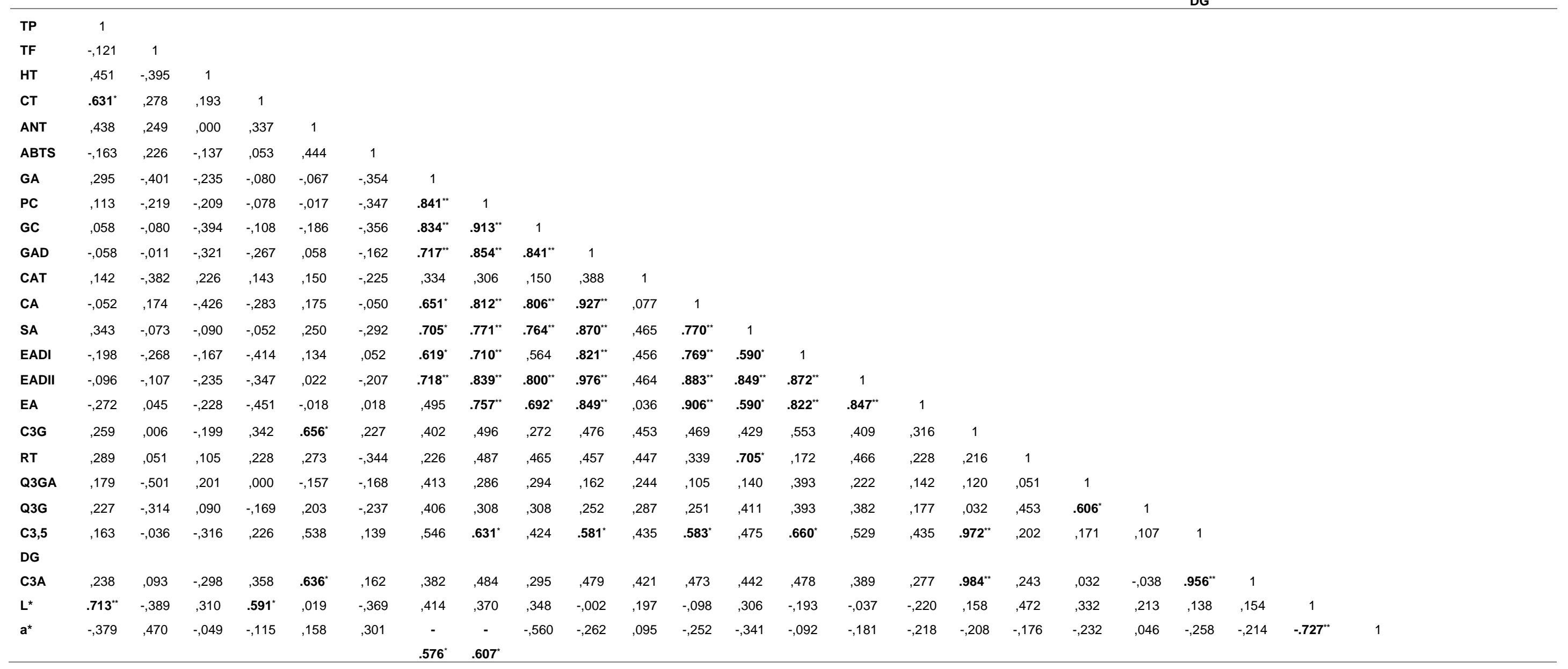




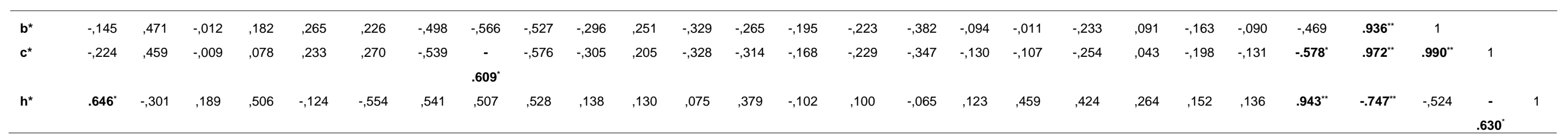

*. Correlation is significant at the 0.05 level; **. Correlation is significant at the 0.01 level; TP : Total phenols; TF : Total flavonoids; HT : Hydrolyzable tannins; CT : Condensed tannins; TA : Total anthocyanins; GA : Gallic acid; PC : Protocatechuic; GC : Gallocatechin; GAD : Gallic acid derivative; CAT : Catechin; CA : Cholorgenic acid; SA : Syringic acid; EADI : Ellagic acid derivative I; EADII : Ellagic acid derivative II; EA : Ellagic acid; C3G : Cyanidin-3-glucoside; RT : Rutin; Q3GA : Quercetin3-galactoside; Q3G : Quercetin-3-glucoside; C3,5D : Cyanidin-3,5-diglucoside; C3A : Cyanidin-3-arabinoside. 


\section{Principal components analysis}

Principal component analysis (PCA) based on correlation coefficients was used to discriminate between variables in the datasets. The aim of this analysis was to determine the main factors to reduce the number of effective parameters to use in classification of the strawberry tree genotypes based on their biochemical parameters. In our study, only a principal component loading of more than $|0.5|$ was considered as being significant for each factor. Total variance of $93.19 \%$ was explained by seven components (Table 6). The first three components consisted of 26 variables, which explained $68.77 \%$ of the total variability observed, which means that these caracters had the highest variation between the genotypes and had the highest impact on discrimination of them. The first component accounted for $36.90 \%$ of the total variance, which is strongly influenced by the protocatechuic (0.97), gallic acid $(0.87)$, gallocatechin (0.89), gallic acid derivative (0.89), chlorogenic acid (0.83), syringic acid (0.86), ellagic acid derivative I (0.76), ellagic acid derivative II (0.86), ellagic acid (0.72), cyanidin-3-glucoside (0.59), rutin (0.51), cyanidin-3,5-diglucoside $(0.70)$, cyanidin-3-arabinoside $(0.57), \mathrm{a}^{*}(-0.58), \mathrm{b}^{*}(-0.53)$ and Chroma $\mathrm{c}^{*}$ $(-0.57)$. The second component accounted for $18.00 \%$ of the total variance and is mainly influenced by total phenols $(-0.60)$, lightness coordinate $\mathrm{L}^{*}(-0.85), \mathrm{a}^{*}(0.65)$, Chroma $\mathrm{c}^{*}(0.55)$ and the hue angle $\mathrm{h}^{\circ}(-$ $0.81)$. The third component represents $13.87 \%$ of the total variation which is defined essentially by total phenols (0.57), condensed tannins (0.77), total anthocyanins (0.80), cyanidin-3-glucoside (0.64) and cyanidin-3-arabinoside (0.64). Generally, these results were in accordance with those reported in previous strawberry tree biochemical studies (Gündoğdu et al., 2018 ; Colak., 2019) [33,30]. They have reported that the biochemical attributes are important in order to evaluate the variation in traits of strawberry tree genotypes. These parameters can be used as a useful tool for selecting genotypes for breeding programs or to recommend new cultivars with superior traits. Scatter plot was prepared according to the first three principal components : PC1, PC2 and PC3, (respectively 36.90, 18 and 13.87 $\%$ of total variance) that discriminate between the genotypes according to their chromatic coordinates and biochemical characteristics (Figure 1). Starting from negative to positive values of PC1, the distribution of genotypes indicated an decrease in the peel lightness, total phenols and condensed tannins. Whereas, starting from negative to positive values of PC2, the most of phenolic compound increased in their values. However, it showed a decrease in the skin coordinates color $\mathrm{a}^{*}, \mathrm{~b}^{*}$ and $\mathrm{c}^{*}$. Starting from negative to positive values of PC3, the distribution of genotypes indicated an increase in the total anthocyanins, total flavonoids, hydrolyzable tannins and ABTS. Our results are in agreement with several studies (Gündoğdu et al., 2018 ; Colak., 2019) (33,30). These studies indicated that high diversity in biochemical traits could be used as an efficient marker system to discriminate between strawberry tree genotypes 
Table 6. Eigenvectors of principal component axes from PCA analysis of studied variables.

\begin{tabular}{|c|c|c|c|c|c|c|c|}
\hline \multicolumn{8}{|c|}{ Component Matrix ${ }^{a}$} \\
\hline & \multicolumn{7}{|c|}{ Component } \\
\hline & 1 & 2 & 3 & 4 & 5 & 6 & 7 \\
\hline Total phenols & .219 & -.597 & .575 & .051 & .085 & .299 & -.060 \\
\hline Total flavonoids & -.257 & .470 & .237 & -.287 & .679 & .108 & .160 \\
\hline Hydrolyzable tannins & -.195 & -.482 & .142 & .413 & -.240 & .199 & -.547 \\
\hline Condensed tannins & -.063 & -.411 & .770 & -.168 & .219 & -.123 & .153 \\
\hline Total anthocyanins & .122 & .273 & .796 & -.090 & -.060 & .427 & -.103 \\
\hline ABTS & -.278 & .453 & .260 & -.353 & -.336 & .385 & -.011 \\
\hline Gallic acid & .871 & -.147 & -.107 & .040 & -.086 & -.092 & .220 \\
\hline Protocatechuic & .966 & -.024 & -.115 & -.055 & .075 & -.068 & -.009 \\
\hline Gallocatechin & .888 & -.040 & -.263 & -.054 & .282 & -.043 & .191 \\
\hline Gallic acid derivative & .888 & .365 & -.124 & .059 & .146 & -.048 & -.098 \\
\hline Catechin & .394 & .074 & .399 & .578 & -.210 & -.488 & -.208 \\
\hline Chlorogenic acid & .829 & .430 & -.142 & -.129 & .193 & .195 & .020 \\
\hline Syringic acid & .858 & .070 & .110 & .214 & .293 & .094 & -.200 \\
\hline Ellagic acid derivative I & .757 & .483 & -.110 & .182 & -.363 & .032 & -.033 \\
\hline Ellagic acid derivative II & .864 & .377 & -.168 & .231 & .085 & -.040 & -.103 \\
\hline Ellagic acid & .719 & .450 & -.355 & -.084 & .024 & .207 & -.152 \\
\hline Cyanidin-3-glucoside & .590 & .255 & .642 & -.265 & -.284 & -.104 & .001 \\
\hline Rutin & .509 & -.130 & .291 & .382 & .509 & .073 & -.218 \\
\hline Quercetin-3-galactoside & .368 & -.299 & -.079 & .392 & -.465 & .159 & .461 \\
\hline Quercetin-3-glucoside & .382 & -.061 & .033 & .692 & -.065 & .416 & .345 \\
\hline Cyanidin-3,5-diglucoside & .696 & .285 & .494 & -.254 & -.274 & -.145 & .102 \\
\hline Cyanidin-3-arabinoside & .575 & .258 & .640 & -.323 & -.168 & -.178 & .021 \\
\hline $\mathbf{L}^{*}$ & .379 & -.854 & .287 & -.004 & .088 & -.012 & .034 \\
\hline$a^{*}$ & -.579 & .650 & .165 & .430 & .091 & -.015 & .106 \\
\hline $\mathbf{b}^{*}$ & -.529 & .485 & .419 & .470 & .186 & -.114 & .160 \\
\hline$c^{*}$ & -.572 & .550 & .341 & .447 & .124 & -.097 & .119 \\
\hline $\mathbf{h}^{*}$ & .493 & -.811 & .133 & .004 & .195 & -.048 & .180 \\
\hline$\%$ of Variance & 36.90 & 18.00 & 13.87 & 9.40 & 6.96 & 4.17 & 3.89 \\
\hline Cumulative \% & 36.90 & 54.90 & 68.77 & 78.18 & 85.14 & 89.31 & 93.20 \\
\hline
\end{tabular}

Eigenvalues higher than $|0.5|$ are marked in bold. 


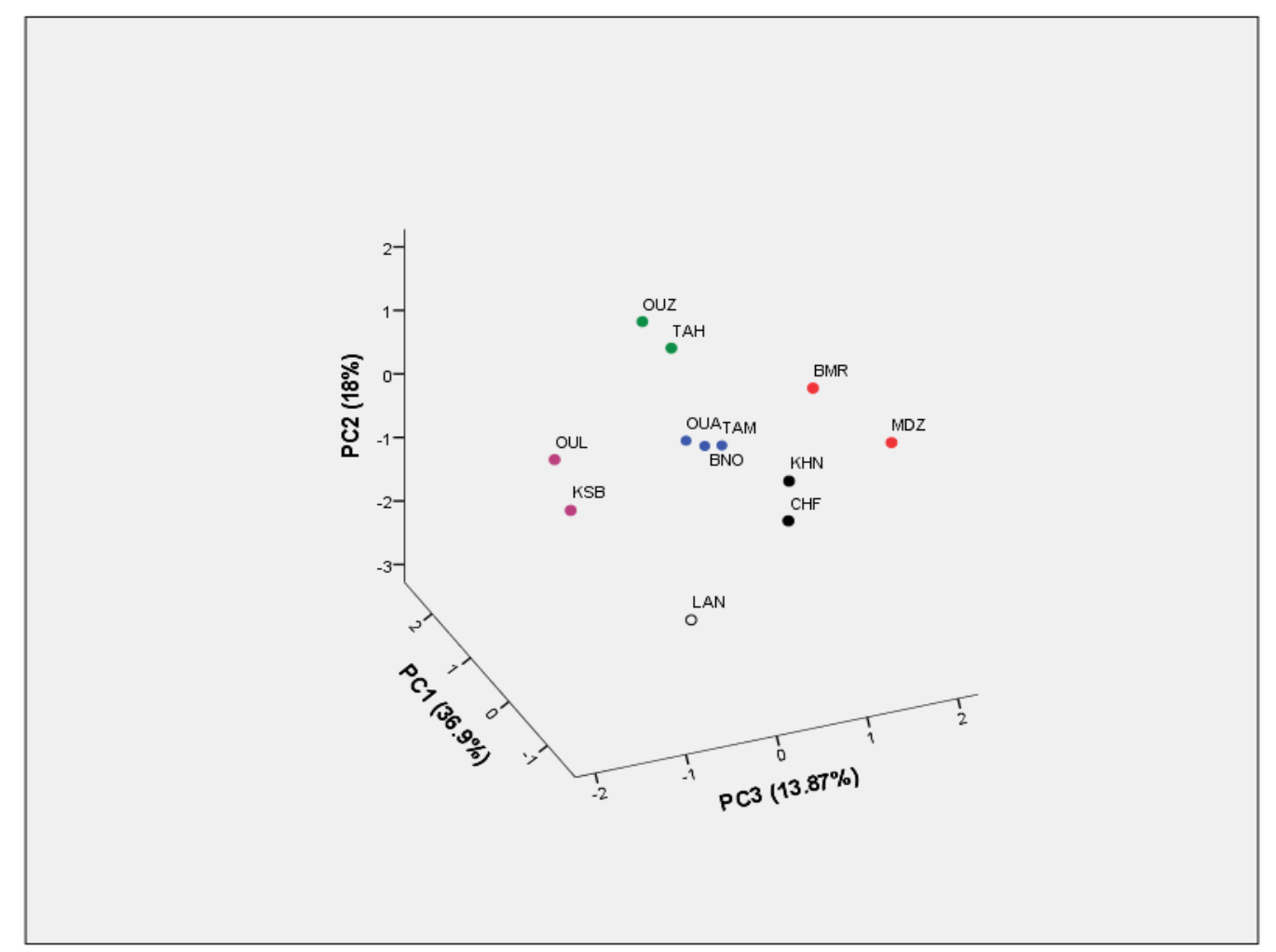

Figure 1. Scatter plot for the first three principal components (PC1/PC2/PC3, 68.77\% of total variance) for the studied strawberry tree genotypes based on their biochemical parameters.

\subsection{Cluster analysis}

Multivariate analysis based on bioactive compounds and antioxidant activity showed high polymorphism among the studied strawberry tree genotypes. Unweighted pair group method (UPGMA) cluster analysis using Euclidean distance coefficient was performed to highlight the similarities among and differences between these genotypes. The genotypes were divided into one main cluster, with a single branch (Figure 2). The genotype "OUZ" was totally discriminated from the cluster. Furthermore, in the main cluster, the genotype "LAN" was the most interesting of the other genotypes and was classified as a singular item. The cluster included 11 genotypes subdivided into four main subgroups. The first subgroup contained "OUL" and "TAH". The second subgroup comprised "CHF" and "MDZ". The tree subgroup contained "KSB" and "BMR". The last subgroup was composed of "TAM", "OUA", "BNO" and "KHN". The findings of the present study showed the high variability within the strawberry tree genotypes based on biochemical parameters. 


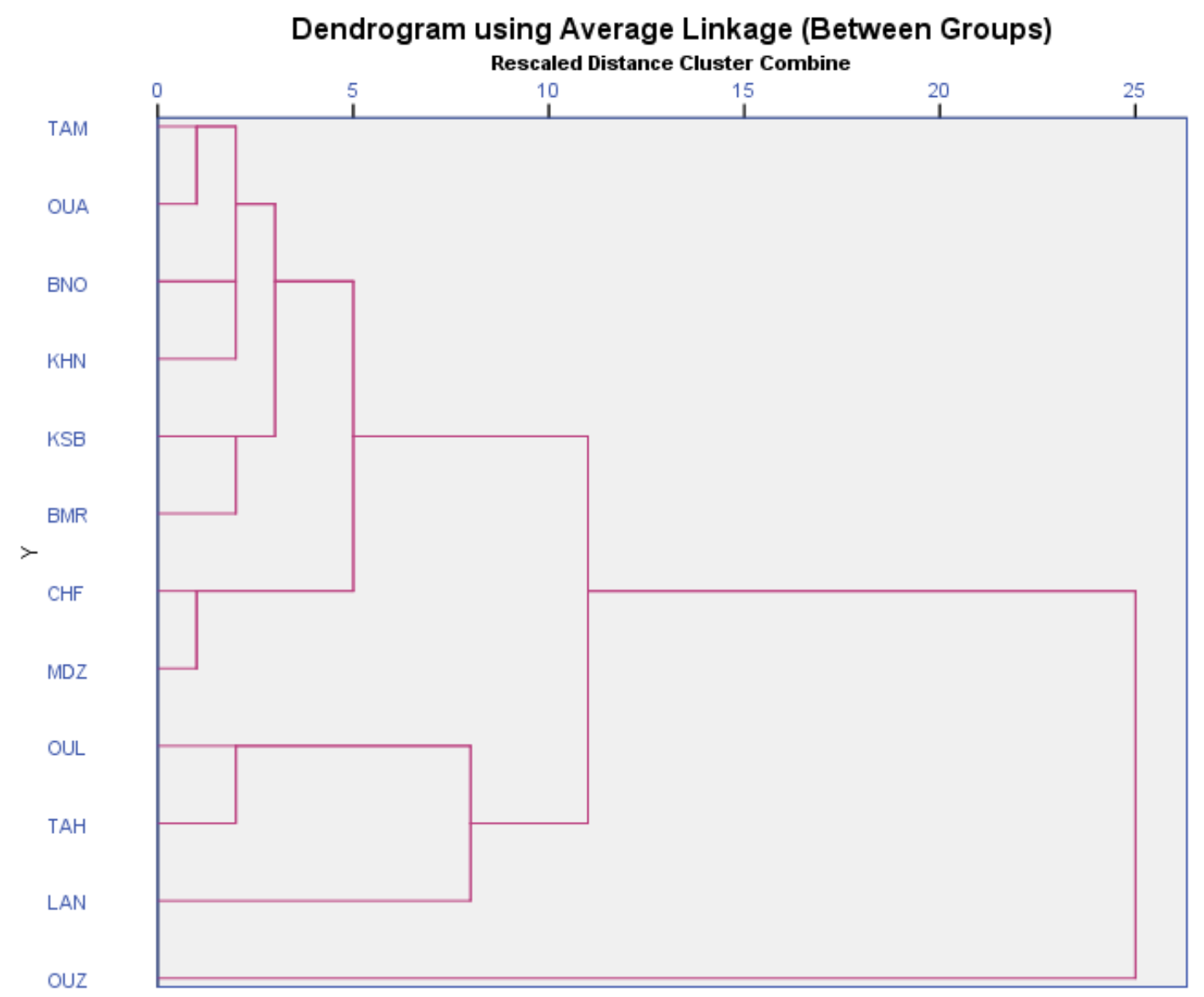

Figure 2. Cluster analysis of the studied genotypes based on the biochemical analysis using squared Euclidian distance method.

\section{Conclusion}

This study proved a high variability among the genotypes studied. The results obtained showed that the strawberry tree fruits are an important source of bioactive compound. Seventeen phenolic compound were identified by HPLC, of which gallocatechol and catechin were the most abundant ones. According to the results obtained, the fruits of strawberry tree can be considered as a very rich source of health-promoting compounds, the fact that may encourage a lot of people to consume them as an alternative source of bioactive compounds. The biochemical composition of the fruits of strawberry tree could also be useful to improve their future pharmacological and cosmetic usages. Besides, The findings confirmed the usefulness and the importance of biochemical parameters and their complementary information to study diversity within the wild inheritance of strawberry tree. Therefore, the results found in this study may be useful to promote the cultivation of species so as to maintain its longevity and diversity as well as to facilitate its use in breeding programs and industrial valorization. The high variability in biochemical composition observed among genotypes could be attributed to genetic factors. Therefore, it will be important to study and identify the genes responsible for the biochemical properties in order to understand the pattern of variation in the biochemical composition of strawberry tree genotypes.

Acknowledgments: This study was supported by the Ministry of high Education, scientist research of Kingdom of Morocco. The authors acknowledge Prof. Manuel Viuda-Martos (Escuela Politécnica Superior de Orihuela. (Universidad Miguel Hernández), Alicante), Spain and Prof.Francisca Hernández (Universidad Miguel Hernández de Elche) for the analytical help and language revision.

\section{References}


1. Celikel, G.; Demirsoy, L.; Demirsoy, H. The strawberry tree (Arbutus unedo L.) selection in Turkey. Scientia Horticulturae. 2008, 118, 115-119.

2. Blanco, E.; Casado, M.A.; Costa, M.; Escribano, R.; García, M.; Génova, M. Los Bosques Ibéricos. Una Interpretación Geobotánica. Planeta, Madrid. 1997.

3. Ziyyat, A.; Legssyer, A.; Mekhfi, H.; Dassouli, A.; Serhrouchni, M.; Benjelloun, W. Phytotherapy of hypertension and diabetes in oriental Morocco. J. Ethnopharmacol.1997, 58, 45-54.

4. Tahraoui, A.; El-Hilali, J.; Israili, Z.H.; Lyoussi, B. Ethnopharmacological survey of plants used in the traditional treatment of hypertension and diabetes in the south-eastern Morocco (Errachidia province). J. Ethnopharmacol. 2007, 110, 105-117.

5. González-Tejero, M.R. Investigaciones etnobotánicas en la provincial de Granada. PhD Thesis. University of Granada. 1990.

6. Mekhfi, H.; El Haouari, M.; Bnouham, M.; Aziz, M.; Ziyyat, A.; Legssyer, A. Effects of extracts and tannins from Arbutus unedo leaves on rat platelet aggregation. Phytotherapy Research. 2006, 20, 135-139.

7. Ziyyat, A.; Mekhfi, H.; Bnouham, M.; Tahri, A.; Legssyer, A.; Hoerter, J.; Fischmeister, R.; Arbutus unedo induces endothelium-dependent relaxation of the isolated rat aorta. Phytotherapy Research. 2002, 16, 572-575.

8. Alarcão-e-Silva, M.; Leitão, A.; Azinheira, H.; Leitão, M. The Arbutus Berry: Studies on its color and chemical characteristics at two mature stages. Journal of Food Compos Anal. 2001, 14, 27-35.

9. Kivçak, B and Mert, T. Quantitative determination of $\alpha$-tocopherol in Arbutus unedo by TLC-densitometry and colorimetry. Fitoterapia. 2001, 72, 656-661.

10. Pallauf, K.; Rivas-Gonzalo, J.C.; Castillo, M.D.; Cano, M.P.; Pascual-Teresa, S.; Characterization of the antioxidant composition of strawberry tree (Arbutus unedo L.) fruits. Journal of Food Composition and Analysis. 2008, 21, 273-281.

11. Barros, L.; Carvalho, A.M.; Morais, J.S.; Ferreira, I.C. Strawberry-tree, blackthorn and rose fruits: Detailed characterisation in nutrients and phytochemicals with antioxidant properties. Food Chem. 2010, 120, $247-$ 254.

12. Serçe, S.; Özgen, M.; Torun, A.A.; Ercişli, S. Chemical composition, antioxidant activities and total phenolic content of Arbutus andrachne L. (Fam. Ericaceae) (the Greek strawberry tree) fruits from Turkey. J. Food Compos. Anal, 2010, 23 , 619-623.

13. Ruiz-Rodriquez, B.M.; Morales, P.; Fernandz-Ruiz, V.; Sánchez Mata, M.C.; Cámara, M.; Díez Marqués, C.; Pardo DeSantayana, M.; Molina, M.; Tardío, J. Valorization of wild strawberrytree fruits (Arbutus unedo L) through nutritional assessment and natural production data .Food Research International. 2011, 44, 12441253.

14. Ayaz, F.A.; Kucukislamoglu, M.; Reunanen, M. Sugar, non-volatile and phenolic acids composition of strawberry tree (Arbutus unedo L. var. ellipsoidea) fruits. Journal of Agricultural and Food Chemistry. $2000,13,171-177$.

15. Pawlowska, A.; M, De Leo M.; Braca, A. Phenolics of Arbutus unedo L. (Ericaceae) fruits: Identification of anthocyanins and gallic acid derivatives.J.Agric.Food Chemistry. 2006, 54, 10234-10238.

16. Mulas, M.; Cani, M.; Brigaglia, N.; Deidda, P. Selezione varietale da popolazioni spontanee per la coltivazione di mirto e coberzzolo in Sardegna. Rivista di Frutticoltura. 1998, 3, 45-50.

17. Takrouni, M.M and Boussaid, M. Genetic diversity and population's structure in Tunisian strawberry tree (Arbutus unedo L.). Sci. Hortic. 2010, 126, 330-337.

18. Molina, M.; Pardo-De-Santayana, M.; Aceituno, L.; Morales, R.; Tardío, J. Fruit production of strawberry tree (Arbutus unedo L.) in two Spanish forests. Forestry. 2011, 84, 419-429.

19. Vidrih, R.; Hribar, J.; Prgomet, Z.; PoklarUlrih, N. The physicochemical properties of strawberry tree (Arbutus unedo L.) fruits. Croat J Food Sci Techno, 2013, 5,(1), 29-33

20. Ben Salem, I.; Ouesletib, S.; Mabrouka, Y.; Landolsic, A.; Saidia, M.; Boulillad, A. Exploring the nutraceutical potential and biological activities of Arbutus unedo L. (Ericaceae) fruits. Industrial Crops and Products. 2018, 122,726-731.

21. Lamaison, J.L and Carnat, A. Teneurs en principaux flavonoids des fleurs de Crataegeus monogyna Jacq et de Crataegeus laevigata (Poiret D. C) en fonction de la vegetation. Pharm. Acta Helv. 1990,65, (11), 315320. 
22. Joslyn, M.A. A serie of monography. Food. Sci. techn. 1970. In : Bessas, A.; Benmoussa, L.; Kerarma, M. Dosage biochimique des polyphenols dans les dattes et le miel récoltés dans le sud algérien. Mémoire d'ingénieur en biologie. Université Djillali Liabes. Sidi belabbas. 2008, 137.

23. Willis, R.B and Allen, P.R. Improved method for measuring hydrolysable tannins using potassium iodate. The Analyst. 1998,123, 435-439.

24. Jackobek, L.; Šeruga, M.; Novak, I.; Medvidovic-Kosanovic, M. Flavonols, Phenolic acids and Antioxidant Activity Of Some Red Fruits. Deutsche Leben smittel Rundschau. 2007,103, 369-378.

25. Giusti, M and Wrolstad, R.E. Characterization and measurement of 1041 anthocyanins by UV-visible spectroscopy, current protocols. Food Chem. Anal. ,2001, 1042, F1.2.1-F1.2.13.

26. Dorman, H.J.D and Hiltunen, R. Fe (II) reductive and free radical scavenging properties of summer savory (Satureja hortensis L.) extract and subfractions. Food Chem. 2004, 88,193-199.

27. Genskowsky, E.; Puente, L.A.; Pérez-Álvarez, J.A.; Fernández-López, J.; Muñoz, L.A.; ViudaMartos, M. Determination of polyphenolic profile, antioxidant activity and antibacterial properties of maqui [Aristotelia chilensis (Molina) Stuntz] a Chilean blackberry. Journal of the Science of Food and Agriculture. , 2016, 96,4235-4242

28. Doukani, K and Tabak, S. Profil Physicochimique du fruit "Lendj" (Arbutus unedo L.). Revue «Nature \& Technologie». B-Sciences Agronomiques et Biologiques. 2015, 12, 53-66.

29. Seker, M and Toplu, C. Determination and comparison of chemical characteristics of Arbutus unedo L. and Arbutus andrachnae L. (family Ericaceae) fruits .Journal of Medicinal Food. , 2010, 13, (4), 1013-1018.

30. Colak, A.M. Morphological and Biochemical Diversity in Fruits of Arbutus unedo L. from East Aegean Region inTurkey. 2019, 61, 379-383.

31. Jurica, K.; Brcic Karaconji, I.; Jurisic Grubesic, R.; Vitali Cepo, D. The nutritional and antioxidant properties of strawberry tree (Arbutus unedo L.) fruit. Food Safety and Quality Congress with international participation. New Achievements and Future Challenges. 2017

32. Bouzid, K.; Toumi Benali, F.; Chadli, R.; Bouzouina, M.; Bouzid, A.; Benchohra, A.; Dif, M.M.; Extraction, Identification and Quantitative HPLC Analysis of Flavonoids From Fruit Extracts of Arbutus unedo L from Tiaret Area (Western Algeria). European Journal of Molecular Biotechnology. , 2014, 6, (4), 160-169.

33. Gündoğdu, M.; Ercisli, S.; Canan, I.; Orman, E.; Sameeullah, M.; Naeem, M.; Ben Aye, R. Diversity in phenolic compound, biochemical and pomological characteristics of Arbutus unedo fruits. Folia Hort., 2018, 30, (1), 139-146.

34. Ganhão, R.; Estévez, M.; Kylli, P.; Heinonen, M.; Morcuende, D. Characterization of selected wild Mediterranean fruits and comparative efficacy as inhibitors of oxidative reactions in emulsified raw pork burger patties. J. Agric. Food Chem. ,2010, 58, 854-8861.

35. Mendes, L.; de Freitas, V.; Baptista, P.; Carvalho, P. Comparative antihemolytic and radical scavenging activities of strawberry tree (Arbutus unedo L.) leaf and fruit. Food Chem. Toxicol., 2011, 49, 2285-2291.

36. Islam, A and Pehlivan, N.F. Pomological properties of strawberry tree (Arbutus unedo) grown in Marmara island. Acad Agric J., 2016,5, 13-20.

37. Badgujar, S.B.; Patel, V.V.; Bandivdekar, A.H.; Mahajan, R.T. Traditional uses, phytochemistry and pharmacology of Ficus carica: a review. Pharm Biol., 2014,52, (11), 1487-1503.

38. Wang, Z.; Cui, Y.; Vainstein, A.; Chen, S.; Ma, H. Regulation of fig (Ficus Carica L.) fruit color: metabolomic and transcriptomic analyses of the flavonoid biosynthetic pathway. Front Plant Sci., 2017,8, 1990

39. Norman, P.E.; Tongoona, P.; Shanahan, PE.; Determination of interrelationships among agrmorphological traits of yams (Discorea spp.) using correlation and factor analyses. J Appl Biosci., 2011, 45, 3059-3070.

40. Podgornik, M.; Vuk, I.; Vrhovnik, I.; Bandelj, D.; Scientia Horticulturae Asurvey andmorphological evaluationof fig (Ficus Carica L.) genetic resources from Slovenia. Sci Hortic., 2010,125, (3), 380-389. 